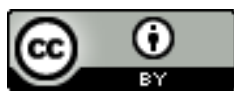

\title{
O PNAIC E SUA CONTRIBUIÇÃO AOS PROFESSORES ALFABETIZADORES SOBRE O SISTEMA DE ESCRITA ALFABÉTICA
}

\author{
THE PNAIC AND ITS CONTRIBUTION TO THE LITERACY TEACHERS \\ ON THE ALPHABETIC WRITING SYSTEM \\ El PNAIC Y SU CONTRIBUCIÓN A LOS PROFESORES ALFABETIZADORES \\ SOBRE EL SISTEMA DE ESCRITA ALFABÉTICA
}

\section{Elaine Korn ${ }^{1}$ \\ Rosana Mara Koerner ${ }^{2}$}

RESUMO: Este artigo apresenta resultados de um estudo que teve como objetivo compreender a contribuição do Pacto Nacional pela Alfabetização na Idade Certa (PNAIC) aos professores alfabetizadores com relação ao Sistema de Escrita Alfabética (SEA) e sobre como esse conhecimento interfere em suas ações didáticopedagógicas. Como instrumentos de coleta de dados foram utilizados questionários com perguntas abertas e fechadas, respondidos por alfabetizadores que atuam do $1^{\circ}$ ao $3^{\circ}$ ano do Ensino Fundamental em uma rede pública de ensino. Também foram realizadas entrevistas semiestruturadas com alguns professores. A pesquisa caracteriza-se como quali-quanti, cujos dados coletados são tratados por meio de uma abordagem qualitativa. Os resultados revelaram que o PNAIC contribuiu para a troca de experiências, para a reflexão sobre a prática pedagógica e estratégias de ensino-aprendizagem. Os professores dizem que a partir do PNAIC houve uma melhor compreensão acerca dos níveis de escrita.

PAlaVRAS-ChaVE: Formação continuada. Pacto Nacional pela Alfabetização na Idade Certa. Sistema de escrita alfabética.

\begin{abstract}
This paper presents results of a study aimed at understanding the contribution of the national pact for alphabetization in right age (Pacto Nacional pela Alfabetização na Idade Certa - PNAIC) to literacy teachers regarding the national alphabetic writing system (Sistema de Escrita Alfabética - SEA) and how this knowledge interfere in their didactic and pedagogical actions. As data collection instruments were used questionnaires with open and closed questions answered by literacy teachers who work from 1st to 3rd year of elementary school in a public school. Also, semi-structured interviews with some teachers were held. The research is characterized as qualitative and quantitative, the collected data were processed by qualitative approach. The results revealed that the PNAIC contributed to the exchange of experiences, to reflect on the pedagogical practice and teachinglearning strategies. Teachers say that PNAIC helped them to improve their understanding about the writing levels.
\end{abstract}

KEYWORDS: Continuing education. National pact for alphabetization in right age. National alphabetic writing system.

RESUMEN: Este artículo presenta resultados de un estudio que tuvo como objetivo comprender la contribución del Pacto Nacional por la Alfabetización en la Edad Cierta (PNAIC) a los profesores alfabetizadores con relación al Sistema de Escritura Alfabética (SEA) y sobre cómo ese conocimiento interfiere en sus acciones didáctico-pedagógicas. Como instrumentos de recolección de datos se utilizaron cuestionarios con preguntas abiertas y cerradas, respondidas por alfabetizadores que actúan del $1^{\circ}$ al $3^{\circ}$ año de la Enseñanza Fundamental en

\footnotetext{
${ }^{1}$ Submetido em: 02/11/2016 - Aceito em: 02/04/2018 - Publicado em: 18/10/2018
}

\begin{tabular}{l|c|c|c|c|c|c} 
(C) Rev. Educ. Perspec. & Viçosa, $M G$ & v.9 & n.1 & p.197-214 & maio/ago.2018 & eISSN 2178-8359 \\
\hline
\end{tabular}


una red pública de enseñanza. También se realizaron entrevistas semiestructuradas con algunos profesores. La investigación se caracteriza como cuali-quanti, cuyos datos recolectados son tratados por medio de un abordaje cualitativo. Los resultados revelaron que el PNAIC contribuyó al intercambio de experiencias, a la reflexión sobre la práctica pedagógica y estrategias de enseñanza-aprendizaje. Los profesores dicen que a partir del PNAIC hubo una mejor comprensión acerca de los niveles de escritura.

PAlabraS Clave: Formación continuada. Pacto Nacional por la Alfabetización en la Edad Cierta. Sistema de escritura alfabética.

\section{INTRODUÇÃO}

A formação continuada de professores vem ganhando espaço prioritário no campo das políticas públicas da educação, sendo amplamente discutida como uma das vias para melhoria da qualidade da educação brasileira em áreas sensíveis. Há uma constatação de que historicamente as crianças concluem a escolarização sem, necessariamente, estarem alfabetizadas, ou seja, sem apresentarem as adequadas habilidades de leitura e escrita (MEC, 2012). Desse modo, o Estado brasileiro reconhece a importância da formação continuada, conforme pode ser observado na Lei $\mathrm{n}^{\circ}$ 9.394, de 20 de dezembro de 1996, no seu Art. 62, § 1: “A União, o Distrito Federal, os Estados e os Municípios, em regime de colaboração, deverão promover a formação inicial, a continuada e a capacitação dos profissionais de magistério" (BRASIL, 1996, s.p.).

Nessa perspectiva, com o intuito de oferecer e assegurar educação de qualidade e garantir a alfabetização plena a todas as crianças brasileiras do primeiro ao terceiro ano do ensino fundamental, o Governo Federal, mediante a Portaria nº 867/2012 do Ministério da Educação (MEC), em parceria com estados e municípios, firmou o compromisso do Pacto Nacional pela Alfabetização na Idade Certa (PNAIC) (BRASIL, 2012b).

Nas variadas mudanças e diferentes caminhos em que a alfabetização vem sendo conduzida no contexto brasileiro, é fundamental que o professor tenha domínio sobre o conceito de alfabetização e as facetas desse processo, para um melhor planejamento da sua ação em alfabetizar. Uma dessas facetas é compreender o Sistema de Escrita Alfabética (doravante SEA) como um sistema notacional, que representa os sons da fala, e não como um código ${ }^{i}$.

Considerando que o ato de alfabetizar requer do professor uma reflexão minuciosa sobre o processo de alfabetização e que sua prática necessita de embasamento teórico, que lhe assegure as condições didático-pedagógicas que promovam uma alfabetização plena, é que se pode perceber a relevância de estudos que busquem compreender de que modo a formação oferecida aos professores alfabetizadores por meio do PNAIC pode contribuir para o aprimoramento da prática docente.

\begin{tabular}{l|c|c|c|c|c|c} 
() Rev. Educ. Perspec. & Viçosa, $M G$ & v.9 & n.1 & p.197-214 & maio/ago.2018 & eISSN 2178-8359 \\
\hline
\end{tabular}


O PNAIC se tornou um tema de interesse para a comunidade acadêmica voltada aos estudos sobre alfabetização e letramento. Em levantamento feito em diferentes bases de dados ${ }^{\mathrm{ii}}$, de 2013 a 2016, tendo como descritores de referência a sigla "PNAIC" e o termo por extenso "Pacto Nacional pela Alfabetização na Idade Certa", foram encontrados 76 trabalhos, abrangendo o período de 2013 a 2016.

De modo geral, os trabalhos encontrados apontam resultados que se delimitaram em entender a implantação do PNAIC e o seu material didático sobre os professores formadores e, em sua maioria, sobre a contribuição do PNAIC para a prática pedagógica, sendo a maior incidência no banco de dados da Associação Brasileira de Alfabetização (ABALF) (29 trabalhos), em que grande parte das pesquisas são artigos de dissertações em andamento.

Nesse sentido, a pesquisa que aqui se apresenta teve como objetivo geral compreender a contribuição do PNAIC aos professores alfabetizadores sobre o SEA e, ainda, buscou verificar como esse conhecimento interfere nas ações didático-pedagógicas em prol da alfabetização. Pretende-se avançar nas discussões em relação à formação continuada do professor alfabetizador, mais especificamente nas repercussões que o PNAIC trouxe para o seu fazer pedagógico.

Inicialmente, são feitas algumas reflexões sobre formação de professores, priorizando a questão da apropriação de saberes necessários ao ato de alfabetizar. Também informações sobre o PNAIC são trazidas. Em seguida, há o detalhamento da metodologia adotada e o delineamento do perfil dos participantes da pesquisa. Na sequência, os dados são analisados, sempre considerando a seguinte questão norteadora: o que os professores alfabetizadores têm a dizer sobre as contribuições do PNAIC para a prática pedagógica a partir do conhecimento do funcionamento do SEA? O artigo encerra com algumas reflexões acerca das possíveis contribuições trazidas pela referida formação continuada ofertada aos professores.

\section{ALGUMAS CONSIDERAÇÕES INICIAIS}

Nos últimos dez anos, tornou-se mais frequente a discussão sobre a formação docente e o interesse pelo fazer do professor (ANDRÉ, 2010). Mais especificamente, tem havido uma maior disposição em ouvir o que o professor tem a dizer sobre o cotidiano escolar e os fatores determinantes da qualidade do ensino e aprendizagem. Como bem nos assegura García (1999), a formação docente se constitui nos processos de formação inicial e continuada, situando o professor como agente pesquisador, investigador, mediador e reflexivo da sua própria prática. 
Para Nóvoa (1995), a formação docente é um processo interativo e dinâmico, sendo fundamental o diálogo entre os professores para consolidar saberes da prática pedagógica. Para esse autor, a formação docente permite:

[...] estimular o desenvolvimento profissional dos professores, no quadro de uma autonomia contextualizada da profissão docente. Importa valorizar paradigmas de formação que promovam a preparação de professores reflexivos, que assumam a responsabilidade do seu próprio desenvolvimento profissional e que participem como protagonistas na implementação das políticas educativas (NÓVOA, 1995, p. 27).

Nesse sentido, reconhecer o desenvolvimento profissional para além da formação permite autonomia, emancipação, desmistifica condutas históricas sobre "ser professor" e fortalece a identidade docente. Permite ao professor ter clareza sobre as características da sua profissão, sobre o que faz, pela possibilidade de decidir sobre a sua ação.

Logo, é importante compreender que a formação docente é caracterizada como uma área do conhecimento comprometida com o processo de ensino e aprendizagem, que possibilita ao professor definir-se como aquele que ensina e é consciente do mandato que a sociedade lhe confia. Nesse sentido, a formação docente é entendida como um processo de desenvolvimento profissional ao longo da vida, para além do desenvolvimento pedagógico, sendo um elemento de estímulo e de luta pelas melhorias da profissão docente.

Não há um conceito fechado sobre o que é formação continuada, sendo um campo em constituição. Nóvoa (1995), Prada et. al. (2010) e Imbernón (2010) discutem-na de maneira ampla e abrangente. Esses autores identificam algumas características importantes que devem ser consideradas na construção de um programa de formação continuada adequado ao profissional de educação. Nóvoa (1995) considera que a formação precisa levar em conta uma dimensão coletiva, em um processo de trocas de experiências. Nesse caso, a interação se dá de maneira que um professor mais experiente desempenhe o papel de formador do professor menos experiente.

Imbernón (2010) destaca que o processo de formação continuada deve estimular uma perspectiva crítico-reflexiva na ação, bem como a valorização do saber do professor como agente da sua formação, em um processo de constituição da sua identidade na profissão docente. Deve-se, também, desenvolver uma formação continuada contextualizada, levando em conta aspectos regionais, culturais e peculiaridades do entorno da comunidade escolar.

Prada et al. (2010) sinaliza que a instituição escolar é o espaço principal para atividades de formação continuada. Entretanto, é necessária uma organização de tempo e espaço para que os professores possam compreender seu contexto escolar, analisar e criar estratégias de intervenção em uma ação docente individual e coletiva. Nesse sentido, o autor esclarece que

\begin{tabular}{l|c|c|c|c|c|c} 
() Rev. Educ. Perspec. & Viçosa, MG & v.9 & n.1 & p.197-214 & maio/ago.2018 & eISSN 2178-8359 \\
\hline
\end{tabular}


o processo de formação continuada pode ocorrer de maneira informal ou dentro de uma estrutura formal.

A formação continuada informal se caracteriza pela iniciativa e envolvimento de pessoas de forma autônoma, resultante das relações interpessoais e fortemente influenciada pela empatia entre os envolvidos. A formação continuada formal se caracteriza por ser institucionalizada, atendendo a normas e leis, dentro de um formato pré-elaborado por um programa, sob uma política. Esse tipo de formação continuada busca produzir documentos oficiais da participação do professor, sendo considerada para fins de progressão de carreira. No que se refere à questão espaço-temporal, essa modalidade pode ocorrer num espaço profissional ou fora dele, desde que esse espaço esteja adequado e em consonância com as normas formais estabelecidas para sua execução.

Historicamente, o MEC vem oferecendo programas formais voltados a problemas em áreas sensíveis da educação brasileira. Entre eles, podem ser citados: Parâmetros em Ação (1999); Programa de formação de professores alfabetizadores (PROFA) (2001); Programa de Apoio à Leitura e Escrita (Praler) (2007); Pró-Letramento (2008) e o Pacto Nacional pela Alfabetização na Idade Certa (PNAIC) (2012).

De modo geral, o objetivo central dessas formações foi/é o de oferecer aos professores alfabetizadores conhecimentos didáticos sobre a alfabetização e melhoria dos níveis de desempenho em leitura e escrita das crianças nessa fase de aprendizagem. De acordo com o seu caderno de apresentação, o Pacto "[...] é constituído por um conjunto integrado de ações, materiais e referências curriculares e pedagógicas, a serem disponibilizados pelo MEC, tendo como eixo principal a formação continuada de professores alfabetizadores" (BRASIL, 2012, p. 5). Essas ações estão organizadas em quatro eixos de atuação:

(1) Formação continuada presencial para os professores alfabetizadores e seus orientadores de estudos; (2) Materiais didáticos, obras literárias, obras de apoio pedagógico, jogos e tecnologias educacionais; (3) Avaliações sistemáticas; e (4) Gestão, controle social e mobilização na busca por assegurar o direito de alfabetização plena a todos os estudantes até o $3^{\circ}$ ano do ciclo de alfabetização (BRASIL, 2012, p. 05).

A estratégia escolhida para realizar o PNAIC baseia-se no conceito de formação continuada, sendo a prática docente do alfabetizador o foco dessa formação. O programa busca uma constante estimulação do professor a partir da reflexão da sua ação pedagógica individual e coletiva:

A formação do professor não se encerra na conclusão do seu curso de graduação, mas se realiza continuamente na sua sala de aula, onde dúvidas e conflitos aparecem a cada dia. Uma das possibilidades de superação de dificuldades é a oportunidade de discutir com outros profissionais da educação, o que pode favorecer a troca de experiências e propiciar reflexões mais aprofundadas sobre a própria prática

\begin{tabular}{l|c|c|c|c|c|c|} 
(C) Rev. Educ. Perspec. & Viçosa, $M G$ & v.9 & n.1 & p.197-214 & maio/ago.2018 & eISSN 2178-8359 \\
\hline
\end{tabular}


(BRASIL, 2012, p. 27). 
Dos 24 cadernos de formação do PNAIC, 3 tratam de forma específica sobre o SEA. O caderno do Ano 1 ( $1^{\circ}$ ano do ciclo de alfabetização) orienta sobre a aprendizagem do SEA; o Ano 2 ( $2^{\circ}$ ano do ciclo de alfabetização) sobre a apropriação ${ }^{\mathrm{iii}}$ do SEA e o Ano 3 ( $3^{\circ}$ ano do ciclo de alfabetização) sobre a consolidação ${ }^{\text {iv }}$ do SEA.

Morais (2005) esclarece que o SEA é um sistema de representação da escrita em segmentos sonoros da fala. Ao entender esse sistema, o professor precisa desenvolver uma prática de alfabetização que estimule em seus estudantes a elaboração mental "da noção de unidades de linguagem (palavra, sílaba, sons menores que a sílaba) para que possam entender as relações entre partes faladas e partes escritas, entre o todo escrito (a palavra) e as partes (letras) que o compõem" (MORAIS, 2005, p. 43).

Soares (2004, p. 97) também destaca que "alfabetizar é muito mais que apenas ensinar a codificar e decodificar", esclarecendo que a alfabetização é uma tecnologia, sendo necessário conhecer as particularidades dessa tecnologia, ou seja, da língua escrita, para desenvolver um trabalho explícito e direto do SEA, estimulando as habilidades de consciência fonológica e propiciando o desenvolvimento da autonomia do estudante nesse processo de apropriação e compreensão do funcionamento desse sistema de escrita alfabética.

Considerando a importância do SEA na prática da alfabetização, é imprescindível que esse tema se encontre no escopo de programas formais voltados à formação continuada de professores alfabetizadores. O PNAIC está em consonância com esse requisito, propiciando a esses profissionais uma formação continuada voltada para os conhecimentos sobre o SEA na perspectiva do letramento, bem como estratégias de ensino-aprendizagem para alcançar os objetivos propostos em cada fase do ciclo de alfabetização. A análise dos dados, adiante, pretende trazer indicativos acerca das contribuições que o conhecimento desse conteúdo trouxe (ou não) para a prática pedagógica dos participantes do referido programa.

\section{PERCURSO METODOLÓGICO}

A metodologia adotada nesta pesquisa combina estratégias quantitativas e qualitativas de maneira complementar, o que a caracteriza como uma pesquisa quali-quanti. De acordo com Triviños (1987, p. 118), “[...] toda pesquisa pode ser, ao mesmo tempo, quantitativa e qualitativa”. Para Gatti (2004, p. 13):

Os métodos de análise de dados que se traduzem por números podem ser muito úteis na compreensão de diversos problemas educacionais. Mais ainda, a combinação deste tipo de dados com dados oriundos de metodologias qualitativas, podem vir a enriquecer a compreensão de eventos, fatos, processos. As duas abordagens demandam, no entanto, o esforço da reflexão do pesquisador para dar sentido ao material levantado e analisado.

\begin{tabular}{l|c|c|c|c|c|c|} 
(C) Rev. Educ. Perspec. & Viçosa, $M G$ & v.9 & n.1 & p.197-214 & maio/ago.2018 & eISSN 2178-8359 \\
\hline
\end{tabular}


Essas modalidades de pesquisas (quantitativa e qualitativa) normalmente se complementam. Não se pode desprezar a articulação entre elas. Apesar de os dados emergirem de um levantamento quantitativo, caracterizado como Survey, eles serão tratados com fundamento em uma abordagem qualitativa, a qual "centra-se na compreensão dos significados atribuídos pelos sujeitos às suas ações" (GATTI; ANDRÉ, 2013, p. 29), buscando interpretar um contexto, considerando que fatos e valores estão intimamente relacionados.

Este estudo utilizou-se de um questionário (survey) como instrumento para coleta de dados que, segundo Babbie (1999), tem como principal característica a obtenção de informações quantitativas sobre dados coletados em larga escala.

Os participantes desta pesquisa são os professores alfabetizadores do $1^{\circ}$ ao $3^{\circ}$ ano do ensino fundamental de um município do norte de Santa Catarina que participaram do PNAIC em 2013, ano em que a formação esteve voltada aos conteúdos de Língua Portuguesa, mais especificamente às questões da alfabetização. Como critério de exclusão dos participantes, contabilizaram-se apenas os questionários dos professores que concluíram a formação e que atuavam na sala de aula do $1^{\circ}$ ao $3^{\circ}$ ano. De acordo com informações da Secretaria de Educação, foram 254 professores alfabetizadores que participaram do PNAIC em 2013. O corpus de análise desta pesquisa ficou constituído de 111 questionários válidos, dos 254 que foram entregues. Dos professores que demonstraram interesse em continuar colaborando com a pesquisa mediante concessão de uma entrevista semiestruturada, foram selecionados três professores de cada ano $\left(1^{\circ}, 2^{\circ}\right.$ e $\left.3^{\circ}\right)$, totalizando nove professores.

Cada um dos 111 questionários recebeu um marcador individual, sequencial, da seguinte forma: P1, P2, P3, [...], P111. Para cada questão aberta foi feita uma classificação de grupos de respostas conforme recorrência, contradição e complementaridade. A partir dessa classificação, foi feita a contabilização das respostas por grupo. Esses dados foram agrupados em indicadores que emergiram das respostas dos professores alfabetizadores.

\section{O QUE OS DADOS DIZEM}

Os professores alfabetizadores participantes deste estudo possuem formação inicial com predominância em Pedagogia (90\%) e especialização com enfoques diversificados. O maior percentual das especializações concentra-se em psicopedagogia e prática pedagógica, o que demonstra que são professores preocupados com o "saber fazer" e comprometidos com o "fazer aprender" dos estudantes. São professores experientes, pois $65 \%$ deles atuam na docência há 6 anos ou mais. No entanto, esses mesmos professores são iniciantes no ciclo de alfabetização: no $1^{\circ}$ ano, $61 \%$ dos professores, e no $3^{\circ}, 70 \%$, ou seja, o ciclo inicial e final de

\begin{tabular}{l|c|c|c|c|c|c|}
\hline (C) Rev. Educ. Perspec. & Viçosa, $M G$ & v.9 & n.1 & p.197-214 & maio/ago.2018 & eISSN 2178-8359 \\
\hline
\end{tabular}


alfabetização é conduzido por professores que estão em um processo de aprendizagem das estratégias de ensino no contexto em que se encontram.

Dos 111 professores, 102 atuam exclusivamente em um único ano, seja $1^{\circ}, 2^{\circ}$ ou $3^{\circ}$, e somente 8 professores se dividem entre duas turmas. Aparentemente, isso facilita ao professor o momento de refletir sobre as estratégias de aprendizagem para a organização do seu planejamento de aula.

A caracterização dos professores alfabetizadores relacionada às suas compreensões sobre como entendem a contribuição do PNAIC sobre o SEA dá indicativos de como as orientações desse programa estão repercutindo no município estudado.

As respostas à questão "Quais as contribuições do PNAIC para sua compreensão sobre o Sistema de Escrita Alfabética?" (uma questão aberta) foram agrupadas por recorrência, chegando-se aos seguintes indicadores: 1. Informa contribuição geral do PNAIC (78 respostas - 57\%); 2. Informa conhecimento prévio sobre o SEA (24 respostas -18\%); 3. Entende o SEA como relacionado aos níveis de escrita (10 respostas - 7\%); 4. Expressa claramente o conhecimento sobre o SEA (7 respostas - 5\%); 5. Associa o SEA à consciência fonológica (1 resposta $-1 \%$ ); e, 6. Sem nenhuma resposta (17 respostas $-12 \%$ ).

O primeiro indicador recebeu respostas genéricas sobre a contribuição do PNAIC, embora a questão tenha sido formulada para saber da contribuição do programa especificamente em relação ao SEA. Ou seja, o professor declara que houve contribuição sem identificar o SEA como parte dessa contribuição:

O curso nos faz (fez) crescer, inovar a dinâmica em sala de aula, repensar e conduzir a prática pedagógica (P28).

Ajudou para melhorar a compreensão, pois através do curso do PNAIC pude perceber algumas modificações que me ajudaram a melhor avaliar cada criança (P5).

Nos fez perceber que a intervenção do professor e seus questionamentos são fundamentais para o avanço (P79).

Conforme análise, os professores citam que a contribuição mais importante do PNAIC foi em relação à "reflexão sobre a prática pedagógica".

Outra contribuição apontada pelos professores indica que o PNAIC trouxe conhecimento em relação à atuação profissional como alfabetizador. Em alguns relatos, os professores mencionam que relembraram conhecimento; para outros, houve consolidação de conteúdos, ou o curso reforçou, ampliou, complementou, aprofundou conhecimento em relação à prática 
pedagógica. Nesse sentido, sobre o conhecimento adquirido no PNAIC, os professores dizem que:

\begin{abstract}
O PNAIC permitiu aprofundar os conhecimentos sobre as propriedades do sistema de escrita, me levando inclusive a chamar a atenção das crianças para tais propriedades; também contribuiu para aprimorar a identificação dos níveis de escrita e as possibilidades de intervenção diante de cada um deles (P111).

Quando eu comecei aqui na escola, comecei com o segundo ano, então a minha cabeça era totalmente tradicional, totalmente voltada ao caderno, muita folha, e com o PNAIC a gente acabou abrindo um pouco a cabeça, a gente trabalha com várias maneiras, a gente pode trabalhar com banco de palavras, construção de próprios gêneros, trazer a prática para a realidade deles; a mãe faz um bolo, o que a mãe usa para fazer um bolo, é uma receita, então a gente conseguiu conciliar bastante essa questão, foi bem válido (P93).
\end{abstract}

Essas falas revelam que alguns professores desenvolviam seu trabalho sem os conhecimentos imprescindíveis para a prática pedagógica de um alfabetizador e outros puderam aprofundar seus conhecimentos, resultando em repercussões na aprendizagem dos estudantes. Essas falas sinalizam para a importância do PNAIC como um programa de formação que possibilitou aos professores (re)pensarem o seu saber-fazer, o que gera um empoderamento ${ }^{\mathbf{v}}$ sobre o seu trabalho. Os discursos sinalizam para o embricamento entre a teoria e a prática, levando os docentes a refletirem sobre essa relação durante a atuação em sala de aula.

O programa parece desenvolver nos professores a preocupação não apenas com o ensinar, mas com o fazer aprender dos estudantes, o que para Roldão (1998) é o sentido do professor se definir como aquele que ensina. É tempo de recolocar a ação de ensinar no seu sentido original, ou seja, ensinar significa "fazer aprender", ou fazer aprender "alguma coisa a alguém”, e justamente por ser um processo complexo e interativo é que se torna necessário que um profissional de ensino tenha clareza sobre o processo de alfabetização. García (2009) situa a profissão docente como uma "profissão do conhecimento", comprometida com o direito de aprender dos alunos.

Garantir o direito de aprendizagem é o objetivo principal do PNAIC, principalmente no que se refere ao ensino da leitura e escrita. Em seus cadernos de formação, há a orientação ao professor alfabetizador do que ele deve Introduzir, Aprofundar e Consolidar em cada ano do ciclo de alfabetização. Em relação a essas etapas, o programa expõe sugestões de como conduzir esse processo com o estudante, que tem um modo de pensar e agir em cada fase do ciclo de alfabetização. É preciso que o professor alfabetizador esteja atento aos saberes experienciais e competências dos seus estudantes para planejar sua prática de modo acessível à compreensão. 
Nessa perspectiva, os dados também revelam que, após a participação no PNAIC, os professores passaram a "refletir sobre o aprendizado da criança", elaborando atividades significativas. Acerca dessa reflexão, P111 diz que:

O PNAIC [...] contribuiu para aprimorar a identificação dos níveis de escrita e as possibilidades de intervenção diante de cada um deles. [...] Na terceira série é cobrado ortografia, no teste no qual aplico com os alunos, grifo as palavras incorretas e pergunto ao aluno o que está errado, exemplo, o aluno escreveu BUXA, sei que o aluno queria escrever BRUXA, neste momento sabe-se que o aluno está alfabético, então trabalho para que haja um avanço ortográfico.

Esse depoimento evidencia que a criança está no centro das preocupações do professor, o qual busca compreender os processos de aprendizagem pelos quais a criança passa para, então, planejar a sua ação de alfabetizar. Essa mudança de "olhar" para a criança resultou em alterações significativas no fazer pedagógico dos professores, principalmente no que se refere à utilização de material concreto e à proposição de atividades lúdicas no processo de alfabetização.

Essas mudanças também podem ser resultado dos momentos de trocas de experiências entre os professores proporcionados pelo PNAIC. Conforme seus dizeres, esse espaço de trocas possibilitou melhor compreensão sobre a sua atuação como alfabetizador, como pode ser observado nas falas a seguir:

O PNAIC contribuiu muito, pois os cadernos abordavam bem os temas de escrita alfabética e as professoras com mais experiências tiravam as dúvidas e falavam sobre sua prática (P34).

Contribuiu muito, pois através do PNAIC tivemos oportunidade de ter muitas trocas de experiências que enriqueceram mais nossa prática pedagógica. Possibilitou também novos conhecimentos para serem aplicados em sala de aula, principalmente os jogos e o trabalho com os gêneros literários (P83).

Ao propiciar um espaço e tempo para essa troca, o PNAIC atende a uma necessidade do profissional da educação para conversar com profissionais da mesma área e série em relação aos desafios do cotidiano da sala de aula, o que proporciona aos professores menos experientes aprenderem com os mais experientes. Nesse sentido, os "saberes experienciais são construídos na e pela prática docente" (TARDIF, 2002, p. 39), e a formação continuada propicia aos professores aprimorarem os saberes da formação inicial por meio das trocas de experiências.

O segundo indicador "Informa conhecimento prévio sobre o SEA" obteve 18\% das respostas à pergunta associada. Nesse caso, os professores informam que já conhecem o SEA de formações das quais participaram anteriormente ao PNAIC, porém não expressam em suas respostas o que, especificamente, sabem sobre o SEA:

\begin{tabular}{l|c|c|c|c|c|c} 
() Rev. Educ. Perspec. & Viçosa, $M G$ & v.9 & n.1 & p.197-214 & maio/ago.2018 & eISSN 2178-8359 \\
\hline
\end{tabular}


Como o PNAIC aborda muito sobre o que aprendi com o PROFA, apenas reforça o que já aprendi antes e relembra estratégias (P70).

Me fez lembrar bastante do PROFA onde o professor precisava saber o que a criança está pensando sobre a escrita e então as intervenções devem ser significativas para que a criança avance (P88).

Eu já sabia, eu fiz o PROFA, fiz a escola da Vila. Eu gosto de me atualizar, mas, principalmente de saber o que as outras escolas estão fazendo de bom. Conversar com pessoas da mesma turma que trabalho, é muito bom participar de tudo isso (P47).

Observa-se que os professores fazem referência de forma positiva ao PROFA, um programa de formação continuada também oferecido pelo Governo Federal, que teve como objetivo oferecer ao professor alfabetizador atividades práticas da ação docente, baseadas em material videográfico e acontecia no formato de módulos. No material de apresentação desse programa não há explicitação quanto à abordagem do SEA.

Os professores afirmam que as formações similares ao PNAIC das quais participaram tiveram importante contribuição para o seu trabalho como alfabetizadores. Falam da complementação de conhecimentos e reforço das estratégias ensinadas nessas formações; contudo, não respondem de forma específica sobre seu conhecimento sobre o SEA, permitindo a inferência de que ou não está claro o que é o SEA ou, ainda, que o PNAIC se repete em relação aos conteúdos dos programas anteriores.

Foram 10 professores que afirmaram que entendem o SEA como relacionado aos níveis de escrita (terceiro indicador):

Compreender os níveis de escrita em que o aluno se encontra, valorizar os avanços e buscar metodologias para superar as dificuldades (P80).

Possibilitou a compreensão das várias fases em que a criança passa até tornar-se alfabética com letramento (P108).

Esses dados evidenciam que o PNAIC possibilitou ao professor alfabetizador formar conhecimento sobre as etapas de aprendizagem pelas quais a criança passa no processo de alfabetização, vivenciando na prática os conteúdos abordados no PNAIC, possibilitando-lhe tirar dúvidas sobre uma demanda do momento, o que não era possível enquanto estudante de Pedagogia, sem vivências da prática. Outra questão evidenciada pelos professores está relacionada ao conteúdo dos cadernos de formação do PNAIC e ao acesso a esses materiais no momento de fazer o planejamento das atividades. Houve aceitação por parte dos professores em relação ao conteúdo dos cadernos e à qualidade do material, pois possivelmente poderão fazer uso das sugestões em sua prática de alfabetização. 
Dos professores, 7 (6\%) reafirmam a importante contribuição do PNAIC em relação ao indicador "Expressam claramente conhecimento sobre o SEA" para a sua formação como professor alfabetizador, não somente com a finalidade da troca de experiências e estratégias para o ensino-aprendizagem, mas também para orientação em relação às bases teóricas pertinentes ao processo de alfabetização, fortalecendo os saberes destinados à realização do planejamento da prática. Conforme salienta Cagliari (2007, p. 9), é de fundamental importância que o professor domine seu ofício de alfabetizador, esclarecendo que:

O processo de alfabetização inclui muitos fatores, e, quanto mais ciente estiver o professor de como se dá o processo de aquisição de conhecimento, de como a criança se situa em termos de desenvolvimento emocional, de como vem evoluindo o seu processo de interação social, da natureza da realidade linguística envolvida no momento em que está acontecendo a alfabetização, mais condições terá esse professor de encaminhar de forma agradável e produtiva o processo de aprendizagem, sem os sofrimentos habituais.

Observa-se esse conhecimento sobre o SEA nas falas dos professores alfabetizadores, mesmo que tenham sido feitas por um pequeno grupo:

O SEA não é um código, mas um sistema notacional. As crianças elaboram hipóteses (escrita) ao tentar escrever e o professor precisa facilitar o contato do aluno com a escrita e ajudá-lo a construir o conhecimento de modo gradativo (P60).

O SEA é quando o aluno se apropria do conhecimento sobre a língua, sobre textos, compreensão de textos orais e escritos, a utilização nas práticas sociais. O aluno tem que entender a relação entre a palavra falada e escrita. E se apropriar do SEA, sendo um processo complexo (P48).

Ocorre quando a criança compreende a organização e funcionamento da escrita e começa a perceber que cada emissão (sonora silábica) pode ser representada na escrita, por uma ou mais letras ou sons (P1).

Não se pode concluir, por meio dessas falas, que somente a minoria dos professores compreendeu o SEA a partir do PNAIC, pois a grande maioria dos participantes exemplificou a sua prática utilizando o SEA, o que nos leva a concluir que eles possuem esse conhecimento, porém não quiseram ou se sentem incapazes de expressá-lo formalmente.

Das respostas relacionadas sobre "o que o conhecimento sobre o SEA influenciou na prática pedagógica”, $85(77 \%)$ professores relataram que esse conhecimento influenciou na prática pedagógica, o que pode ser observado nas respostas a seguir:

Influenciou de maneira positiva. A partir do curso, prestei mais atenção aos níveis de escrita, preparando atividades mais adequadas, respeitando os níveis de escrita (P25).

A importância de fazer atividades conforme o nível de escrita (P31). 
Eu mesma me dei conta de algumas propriedades do sistema de escrita que até então eu desconhecia, e passei a explorá-las em sala (P111).

Os professores modificaram as suas práticas no sentido de estarem mais atentos aos níveis de escrita, preparando atividades de forma a considerar cada nível de escrita, em uma perspectiva de estimular as habilidades de consciência fonológica, e eles demonstraram conhecimento sobre tais habilidades:

A criança descobre ou percebe a lógica da escrita percebendo a correspondência entre a representação escrita das palavras e as propriedades sonoras das letras, usando ao escrever uma ou mais letras para cada emissão sonora, percebe os sons de cada sílaba para formar a palavra (P1).

Aprendi que para o desenvolvimento da consciência fonológica é interessante utilizar de jogos, como por exemplo, o caça rimas, é um jogo que tem como principal objetivo desenvolver essa habilidade, por meio da exploração de rimas, comparar palavras quanto às semelhanças sonoras (P81).

A consciência fonológica está relacionada à reflexão sobre a construção da escrita, sobre as propriedades desse sistema. É tomar consciência da estrutura de uma palavra (P111).

Nessa perspectiva, é essencial que a criança seja desafiada a refletir sobre a escrita de forma a perceber as correspondências sonoras das palavras, oportunizando a ela a participação mais ativa no processo de alfabetização. Há professores que dizem que o conhecimento sobre o SEA influenciou muito pouco (11\%) e não influenciou (3\%) em sua prática de alfabetização, como se observa nas falas a seguir:

Já possuía uma boa prática de alfabetizar alcançando êxito com $95 \%$ dos alunos ao final do $1^{\circ}$ ano (P4).

Já tinha feito outros cursos que tinham proposta parecida com a do PNAIC. E já colocava em prática (P20).

Constatou-se que esses dizeres são de professores experientes de um município do norte de Santa Catarina, o que justifica tal afirmação nas falas pelo tempo de serviço que exercem.

Os professores alfabetizadores indicam que, a partir de sua compreensão do SEA, há um melhor aproveitamento do material didático (jogos e livros de literatura infantil) fornecido pelo MEC. Fica evidente, no relato da prática, a articulação das propriedades do SEA com materiais concretos, como recursos facilitadores da aprendizagem:

Vieram vários jogos em uma caixa para auxiliar na alfabetização de uma forma lúdica e esses jogos são muito bons e eficazes. O bingo do som inicial e o bingo da letra inicial são exemplos de jogos que utilizo em sala. Estes jogos possuem entre seus objetivos os de dominar as correspondências som-grafia, identificar os fonemas, estabelecer correspondência fonográfica e perceber que palavras que possuem a mesma sequência de sons tendem a ser escritas com a mesma sequência de letras. Estes jogos eu realizo em duplas (P25).

\begin{tabular}{l|c|c|c|c|c|c} 
(C) Rev. Educ. Perspec. & Viçosa, $M G$ & v.9 & n.1 & p.197-214 & maio/ago.2018 & eISSN 2178-8359 \\
\hline
\end{tabular}


Os materiais utilizados pelos professores apresentam repertório lúdico e concreto, com o objetivo de tornar a aprendizagem mais prazerosa, estimulando as habilidades de consciência fonológica para apropriação do SEA. Por meio dos dizeres dos professores, observa-se que o PNAIC contribuiu de forma significativa para "formar, aprofundar e consolidar conhecimentos sobre o SEA", o que permite ao professor ter mais propriedade para melhor planejar e conduzir o seu fazer pedagógico.

\section{CONSIDERAÇÕES FINAIS}

Os dados desta pesquisa revelam que os professores alfabetizadores, em sua maioria, são experientes pelo seu tempo de serviço, porém iniciantes no ciclo de alfabetização. Nesse sentido, os professores relatam que o PNAIC contribuiu principalmente para a troca de experiências entre os participantes, visto que estão em processo de adaptação nesse novo contexto de ensino, com novos objetivos de aprendizagem a serem cumpridos.

Uma investigação mais aprofundada, em um trabalho futuro, poderá ser aplicada em buscas de respostas para perguntas, tais como: por que os professores experientes são iniciantes no ciclo de alfabetização? O que determinou essa ocorrência? Quais são os aspectos positivos e negativos resultantes?

A partir dos relatos dos professores alfabetizadores, os principais resultados são que o PNAIC propiciou uma formação continuada de forma a instrumentalizar o professor para a sua atuação profissional. O programa contribuiu significativamente para um melhor planejamento e organização das atividades, as quais têm como base estimular as habilidades de consciência fonológica para a apropriação do SEA.

Os professores referem que o PNAIC contribuiu para compreender os estágios de escrita pelos quais a criança passa durante o processo de alfabetização e possibilitou repensar as formas de conduzir o ensino e a avaliação. Outra questão positiva apontada pelos professores está relacionada às sugestões de estratégias de ensino, as quais influenciaram fortemente para mudanças na prática, tais como: uso de materiais concretos, jogos, brinquedos e brincadeiras no dia a dia da sala de aula, algo que antes não era comum. Observa-se que, após a participação no PNAIC, o professor está mais atento com o fazer aprender do estudante.

Contudo, é prematuro prever grandes mudanças neste momento, pois os professores estão praticando os conhecimentos adquiridos no PNAIC, sendo necessário um período de maturação da aplicação dessa proposta para que se possa chegar a um denominador.

Com a realização desta pesquisa, observou-se que o campo de estudo sobre o PNAIC e a sua

\begin{tabular}{l|c|c|c|c|c|c} 
(C) Rev. Educ. Perspec. & Viçosa, $M G$ & v.9 & n.1 & p.197-214 & maio/ago.2018 & eISSN 2178-8359 \\
\hline
\end{tabular}


contribuição aos professores alfabetizadores sobre o Sistema de Escrita Alfabética ainda está relativamente inexplorado, o que deve motivar o desenvolvimento de mais trabalhos que venham a formar conhecimento nesse campo.

Esse movimento de políticas de formação continuada contribui para a qualificação profissional do professor em exercício diante de uma sociedade em constante mudança e dos (des)caminhos que a alfabetização tem percorrido nas últimas décadas.

\section{REFERÊNCIAS}

ANDRÉ, Marli. Formação de professores: a constituição de um campo de estudos.

Educação. Porto Alegre, v. 33, n. 3, p.174-181, set./dez. 2010.

BABBIE, Earl. Métodos de pesquisas de Survey. Belo Horizonte: Editora UFMG, 1999.

BRASIL. Ministério da Educação. Secretaria de Educação Básica. Pacto Nacional pela

Alfabetização na Idade Certa: formação do professor alfabetizador: caderno de apresentação/Ministério da Educação, Secretaria de Educação Básica, Diretoria à Gestão Educacional. Brasília: MEC, SEB, 2012.

BRASIL. Ministério da Educação. Secretaria de Educação Básica. Regulamentação da formação continuada ao magistério. Lei n ${ }^{\circ}$ 9.394, de 20 de dezembro de 1996, no seu Art. 62, § 1. 1996. Disponível em: <http://www.planalto.gov.br/ccivil_03/leis/19394.htm>. Acesso em: 15 maio 2015.

BRASIL. Ministério da Educação. Secretaria de Educação Básica. Portaria nº 867, 4 de julho de 2012. Institui o Pacto Nacional pela Alfabetização na Idade Certa e as ações do Pacto e define suas diretrizes gerais. Diário Oficial da União, Brasília, 05 de julho de 2012. 2012b. Disponível em: <http://pacto.mec.gov.br/images/pdf/port_867_040712.pdf>. Acesso em: 19 jan. 2016.

CAGLIARI, Luiz Carlos. Alfabetização \& Linguística. Editora Scipione, 2007.

GARCÍA, Carlos Marcelo. Formação de professores: para uma mudança educativa. Colecção Ciências da educação Século XXI. Porto, Portugal: Porto Editora, 1999.

GARCÍA, Carlos Marcelo. A Identidade docente: constantes e desafios. Revista Brasileira de Pesquisa Sobre Formação Docente, Belo Horizonte, Autêntica, v.1, p. 109-131, ago/dez 2009.

GATTI, Bernadete; ANDRÉ, Marli. A relevância dos métodos de pesquisa qualitativa em Educação no Brasil. In: WELLER, Wivian; PFAFF, Nicolle (Orgs.). Metodologias da pesquisa qualitativa em educação: teoria e prática. Petrópolis, RJ: Vozes, 2013. P. 29-38.

\begin{tabular}{l|c|c|c|c|c|c} 
() Rev. Educ. Perspec. & Viçosa, MG & v.9 & n.1 & p.197-214 & maio/ago.2018 & eISSN 2178-8359 \\
\hline
\end{tabular}


GATTI, Bernadete; ANDRÉ, Marli. Estudos quantitativos em educação. Revista Educação e Pesquisa, São Paulo, v. 30, n. 1, p. 1-30, jan./abr. 2004.

IMBERNÓN, Francisco. Formação continuada de professores. Porto Alegre: Artmed, 2010.

MORAIS, Artur Gomes de. Se a escrita alfabética é um sistema notacional (e não um código), que implicações isto tem para a alfabetização? In: MORAIS, Artur Gomes de; ALBUQUERQUE, Eliana; LEAL, Telma. Alfabetização: apropriação do sistema de escrita alfabética. Belo Horizonte: Editora Autêntica, 2005, P. 29-45.

NÓVOA, Antônio (Coord.). Os professores e a sua formação. 2. ed. Lisboa: Dom Quixote, 1995.

PRADA, Alvarado Eduardo Luiz; FREITAS, Thaís Campos; FREITAS, Cinara Aline. Formação continuada de professores: alguns conceitos, necessidades e propostas. Rev. Diálogo Educacional, Curitiba, v. 10, n. 30, p. 367-387, maio/ago. 2010.

ROLDÃO, Maria do Céu. Que é ser professor hoje? - a profissionalidade docente revisitada. Revista das ESES, n. 9, p. 79-87, 1998. (Nova série).

SOARES, Magda. Alfabetização e Letramento: Caminhos e descaminhos. Revista Pátio, Porto Alegre, ano 8, n. 29, p. 18-22, fev./abr. 2004.

TARDIF, Maurice. Saberes docentes e formação profissional. Petrópolis, RJ: Vozes, 2002.

TRIVIÑOS, Augusto Nibaldo Silva. Introdução à pesquisa em ciências sociais. São Paulo: Atlas, 1987.

\section{NOTAS}

${ }^{\text {i }}$ Código é um conjunto de símbolos substitutos de um sistema notacional já existente, e para aprendê-lo é preciso decorá-lo.

ii Os lócus de investigação foram as bases de dados da Coordenação de Aperfeiçoamento de Pessoal de Nível Superior (CAPES), as pesquisas da Associação Nacional de Pós-Graduação e Pesquisa em Educação (ANPEd), a Biblioteca Científica Eletrônica do SciELO (Scientific Eletronic Library Online), Biblioteca Digital de Teses e Dissertações (BDTD), Associação Brasileira de Alfabetização (ABALF) e os trabalhos publicados no Congresso Nacional de Educação (EDUCERE).

iii Significa compreender um determinado conhecimento e apoderar-se dele (BRASIL, 2012).

${ }^{\text {iv }}$ De acordo com o dicionário Michaelis, consolidação é o processo de transformar. No que se refere aos direitos de aprendizagem, é apropriar-se de um conhecimento.

v O termo "empoderamento" utilizado refere-se ao conhecimento do professor, ao saber fazer pedagógico.

\begin{tabular}{l|c|c|c|c|c|c} 
(C) Rev. Educ. Perspec. & Viçosa, $M G$ & v.9 & n.1 & p.197-214 & maio/ago.2018 & eISSN 2178-8359 \\
\hline
\end{tabular}




\section{Sobre as autoras}

1 Elaine Korn: Mestre em Educação pela Universidade da Região de Joinville. E-mail: korn.eliane@gmail.com - ORCID: http://orcid.org/0000-0002-3203-1528

${ }^{2}$ Rosana Mara Koerner: Mestre e doutora em Linguística Aplicada pela Universidade Estadual de Campinas. Professora pela Universidade da Região de Joinville. E-mail: rosanamarakoerner@ hotmail.com - ORCID: http://orcid.org/0000-0002-2523-6744 